\title{
Nueva gerencia pública: ¿gobierno sin política?
}

\author{
Guerrero, Omar* \\ * Profesor de Carrera en Administración Pública de la Facultad de Ciencias Políticas y \\ Sociales de la Universidad Nacional Autónoma de México. Miembro del Instituto Nacional \\ de Administración Pública y de la Academia Mexicana de Ciencias. Investigador Nacional \\ Nivel III. E-mail: omarg@servidor.unam.mx.
}

\section{Resumen}

Recientemente el concepto de gerencia pública (public management) ha provocado un singular debate. El propósito de este trabajo es analizar la nueva gerencia pública con el propósito de contribuir al debate. Los resultados revelan lo siguiente sobre la nueva gerencia pública: 1) Es una visión privada de lo público, de naturaleza cataláctica porque brota del pensamiento económico clásico, que la sitúa en el mercado para sustituir el esquema burocrático, 2) Se obstenta como nueva pero sus antecedentes son tan antiguos como la economía clásica y neoclásica, 3) En ella convergen una variedad de ingredientes pero de igual naturaleza que la hacen compleja, 4) Su arribo es consonante con los tiempos actuales cuando se proponen soluciones económicas a los problemas políticos en una atmósfera donde el estudio de la política se distancia de la economía, 5) Son conceptos fundacionales: orientación al cliente, privatización, mercado y competencia y en la reforma del sector público: enfoque empresarial-gerencial, gerencia por objetivos y resultados y agenciación y reducción de costos, 6) Situada en el mercado, paradójicamente desde dentro es activada por la gerencia y da paso a reglas burocráticas, reemplazando al gobierno de los hombres, visión romántica de un gobierno sin política.

Palabras clave: Nueva gerencia pública, administración pública, mercado, burocracia, política.

\section{New Public Management. Government Without Policy?}

\section{Abstract}

Recently the concept of public management has provoced much debate. The purpose of this paper is to analyze new public management for the purpose of contributing to this debate. The results reveal the following aspects in relation to new public management: 1 ) There is a new private vision of what is public, catalytic in nature, which emerges from classical economic thought, and which situates itself in the market in order to substitute 
the bureaucratic scheme, 2) It pretends to be new but its antecedents are as old as classical and neo-classical economics, 3) A variety of ingredients converge in this new concept but of a similar nature which makes it complex, 4) Its arrival coincides with modern times when when economic solutions are proposed for political problems in an atmosphere where the study of policies has separated itself from the study of economics, 5) There are fundamental concepts: orientation of the client, privatization, market and competition, and the reform of the public sector; the management focus, management by objectives-results, agencies, and cost reduction, 6) It is situated in the market-place, paradoxically activated from within by management, and gives way to bureaucratic rules, re-emplacing government by men, a romantic vision of a government without policy.

Key words: New public management, public administration, market, bureaucracy, policy.

Recibido: 03-06-20. Aceptado: 03-07-20

\section{I ntroducción}

Antes de iniciar este artículo debe ser explicado el sentido de su subtítulo, el cual me fue inspirado por una frase de James Buchanan (1991: 217), a través de la cual explica que la opción pública (public choice) se ha convertido en una teońa del gobierno, la cual, habiendo comenzado por plantear análisis y soluciones románticas e ilusorias sobre el funcionamiento del gobierno y el comportamiento de los gobernantes, los ha reemplazado por nociones que entra ñan más escepticismo acerca de lo que los gobiernos pueden hacer. La opción pública, por lo tanto, ha tendido a ser más consistente con la realidad. En nuestro caso, esperamos que la nueva gerencia pública sea capaz de plantear sus propuestas sin romances, pues hasta ahora parece inveteradamente propensa a proponer soluciones difícilmente aplicables.

El concepto de gerencia pública (public management) ha sido tradicionalmente una parte del ámbito disciplinario de la administración pública que lo ha enriquecido, y colaborado a extender el dominio de su argumentación científica. Sin embargo, recientemente ese concepto ha provocado un singular debate de alcances universales e incluso un movimiento de independencia académica.

Inherente a la cultura administrativa anglosajona en Estados Unidos de América y el Reino Unido, así como Canadá, Australia y Nueva Zelanda, dicha gerencia hoy en día constituye un foco conceptual peculiar. Incluso buena parte de los sectores definitorios de la administración pública en los textos clásicos la mencionan de manera muy principal. 
Sin embargo, desde principios de la década de 1990 ese fenómeno emergió bajo una interpretación inédita que ha tendido a diferenciarse por su novedad; es decir, como una nueva gerencia pública que toma distancia radical de la antigua idea del manejo (management) como un elemento definitorio de la administración pública. Bajo su nuevo ideario, la gerencia pública es concebida como opuesta de la administración pública, y más particularmente, se le entiende como una transdisciplina económica que puede sustituirla benéficamente.

En estas páginas nos hemos propuesto analizar la esencia de la nueva gerencia pública, con el propósito de contribuir a dar claridad a su significado, principios y alcances.

\section{Lo nuevo, lo gerencial y lo público}

La nueva gerencia pública consiste en una palpable novedad por su origen, por su configuración como paradigma y por los efectos que ha provocado.

En primer lugar, la nueva gerencia pública constituye una visión privada de lo público que ha brotado de una tradición diversa a la establecida por Frederick Taylor (1911), Henri Fayol (1931), Oliver Sheldon (1986), y Chester Barnard (1975), mundialmente conocida como Movimiento del Manejo Científico. Tampoco se relaciona con los trabajos de Donald Sayles (1964) Henry Mintzberg (1983), ni John Kotter (1982) acreditados estudiosos contemporáneos de la gerencia privada. Sólo está familiarizado con el pensamiento de Peter Drucker (1986; 1969) hoy en día uno de los tratadistas más reconocidos de la administración de los negocios privados.

El origen de la nueva gerencia pública se encuentra en otro lado: ha brotado de la economía, y más particularmente, del pensamiento económico neoclásico engendrado en la escuela austríaca, así como de la opción pública (public choice) estadounidense, donde se exalta lo privado, el individualismo y la rentabilidad. Por lo tanto, aunque la nueva gerencia ostenta como apellido el vocablo público, nada la vincula a esa noción, pues sus propósitos y resultados se encaminan a la privatización del Estado.

En segundo lugar, aunque lleva por nombre la voz gerencia, no es ella en el sentido clásico su fundamento, sino la noción de mercado, al cual propone como modelo sustituto del esquema "burocrático" del Estado. Aquí tienen su origen las propuestas a favor de: 1) Establecer mercados intra-gubernamentales y orientar al gobierno hacia el consumidor, no hacia el ciudadano; 2) Desarrollar la competencia en la provisión de bienes y servicios públicos y 3) Introducir al "espíritu empresarial" en el gobierno. 
En efecto, la neogerencia pública no ha desarrollado una teoría del management en el sentido de los autores precitados, porque su carácter es constituir una interfase entre el Estado y la sociedad a través del mercado, no tanto para auscultar las entrañas organizativas del gobierno. De aquí su naturaleza cataláctica, es decir, un proceso signado por el intercambio.

Se trata de un modelo de dentro hacia fuera, no de fuera hacia dentro.

Finalmente, la nueva gerencia pública se ostenta como nueva. Sin embargo, sus antecedentes son tan rancios como antigua es la economía clásica y neoclásica. En efecto, tal como lo observaremos más adelante, sus conceptos centrales son categorías económicas pletóricas de abolengo: la noción de competencia fue formulada por Adam Smith (1952) durante el último cuarto del siglo XVIII (1776), en tanto que la ley del mercado la ideó Jean-Baptiste Say (1841). El concepto de empresario fue acuñado por Richard Cantillon (1950) dos décadas (1755) antes de que apareciera la obra monumental de Smith. En fin, la teoría de la soberanía del consumidor la desarrolló Ludwig von Mises (1988), desde principios de la década de 1940.

La nueva gerencia pública, no obstante, constituye un fenómeno de alta complejidad. Ello obedece en primer lugar, a que además de esos conceptos, en su seno convergen una variedad de ingredientes, los cuales, aunque de la misma naturaleza, o emparentados íntimamente, tienen personalidad propia y autonomía relativa. Hay que resaltar sobre todo a la economía neoclásica, donde repuntan como sustento principal la escuela austríaca y la opción pública. La presencia de la primera es observable principalmente a través de la obra de Ludwig von Mises (1994), y Friedrich Hayek (1967). En la segunda son muy visibles James Buchanan (1991), Gordon Tullock (1965) Vincent Ostrom (1974) y William Niskaken (1971). También está presente el pensamiento administrativo de Peter Drucker (1969; 1986), y una cantidad apreciable de conceptos sobrevivientes de la administración pública que han sido rebautizados. Fuera de la atmósfera anglosajona se debe rendir debido crédito a los franceses Octave Gelinier (1967), Michel Messenet (1975), y Romain Laufer y Alain Burlaud (1980), quienes formularon el esquema esencial del nuevo manejo público varias décadas antes de que apareciera en el Reino Unido y Estados Unidos de América.

\section{Fisiocracia y Antropocracia}

El arribo de la nueva gerencia pública es consonante con los tiempos actuales, pues hoy en día se suele proponer que los problemas políticos tengan soluciones económicas, y que una vez reemplazados los procesos burocráticos, el gobierno se oriente a través del 
mercado. Consiguientemente, las soluciones económicas de los problemas políticos se están explayando en una atmósfera dentro de la cual el estudio de la política se distancia de la economía. Esta situación tiene su origen tiempo atrás, arrancó en la gradual y todavía irreversible tendencia a la especialización disciplinaria, separando al temario político y al temario económico que han tendido a distanciarse más y más, y aún, a disociarse.

El resultado de esa brecha es el olvido de ese escenario llamado arte del gobierno, donde antaño se trababan las relaciones entre la política y la economía, y donde se daba sentido a la intervención económica del Estado. La exclusión del arte del gobierno ha derivado en el ensanchamiento de una antigua brecha entre la gerencia, entendida como una emanación de las relaciones de producción, y la administración pública discernida como un efecto de las relaciones de dominación. A esta fisura hay que añadir la emergencia del modelo neogerencial, caracterizado por un manejo emanado de las relaciones de intercambio. Su ideario tiene como base desechar el gobierno político, y en su lugar, asumir ese gobierno económico que se llama mercado, de manera que cada administración pública individual quede uniformada bajo un patrón universal. La nueva gerencia pública - un manejo cataláctico que opera en el ámbito del intercambio mercantil - proclama al mercado como el mecanismo de cooperación espontáneo y automático que hace funcionales los procesos económicos sin el concurso de administración alguna. Pero no siendo la administración pública una consecuencia de la colaboración espontánea, ni de los procesos automáticos, sino de mecanismos coercitivos, jerárquicos y conscientes, el problema teórico esencial del gobierno de hoy en día consiste en cómo transitar de un sistema deliberado, a un régimen espontáneo, y hasta dónde esto es posible y deseable.

El problema referido plantea asuntos ciertamente trascendentales. Uno muy principal es la estrechez de los enfoques puros en las ciencias sociales, que del mismo modo como lo desarrolló Hans Kelsen, bajo la forma de la teoría pura del derecho, otros campos del saber también se esfuerzan por alcanzar conocimientos validados sólo desde dentro.

No está de más que expliquemos brevemente el significado de la pureza de la teoría del derecho de Kelsen (1933), así como las ideas de Karl Schmitt (1985), sobre lo político, pues a través de su espíritu podremos entender la naturaleza de los enfoques puros y su alcance.

El jurista austriaco explicó que la teoría jurídica pura es la teoría del derecho positivo, la cual se limita a conocer única y exclusivamente su objeto, a saber: qué es y cómo es el derecho, no cómo debe ser o cómo puede ser construido. Es pura la teoría referida porque 
se propone asegurar un conocimiento preciso del derecho como su única finalidad, excluyendo todo aquello que rigurosamente no es derecho. La teoría pura del derecho libera a la ciencia jurídica de los elementos que le son extraños. Con esta medida, el derecho deja de estar mezclado con la ética, la psicología o la teología (Kelsen, 1933: 910).

Tan pura como la doctrina kelseniana es la teoría de lo político desenvuelta por Karl Schmitt (1985), que debe ser deslindada del concepto de la política. En efecto, lo político no tiene un objeto ni posee límites, pues se trata de un concepto más libre y amplio que la política, toda vez que esta categoría fue castrada por el liberalismo que prohijó a la economía clásica y neoclásica, pues la subordinó a ella (Frye, 1996: 821-822). Es tan ilimitado lo político que no existe organización alguna que lo comprenda, incluso el Estado. Sencillamente lo político refiere la relación amigo-enemigo, cuyo laxo acotamiento es el grado de intensidad de su asociación o disociación, y que puede llegar hasta la muerte del otro (Schmitt, 1985:22-23). Por consiguiente, sólo se puede definir lo político a través de categorías propiamente políticas, pues tienen sus propios criterios que se expresan con independencia de otras realidades sociales, tales como las expresiones del acontecer y el pensamiento humanos de tipo moral, estético o económico.

Tal es la forma como Schmitt separó la teoría pura de la política (la política por la política) de la teoría liberal de la política (la política por la economía), que no hizo sino "despolitizar" a la política, pues su ámbito vital es la esfera individual y privada, no lo público ni las ideas políticas (Frye, 1966: 822 -825).

En un contexto en el cual han proliferado los movimientos de independencia de cada una de las ciencias sociales, deslindándose de sus hermanas, las concepciones puras tendieron a proliferar. Naturalmente la economía clásica y neoclásica también han constituido un modelo glorificado de pureza, toda vez que desde hace dos centurias la primera proclamó la legalidad intrínseca de los procesos económicos. Esta versión se inició con la segregación de todo intervencionismo del Estado y la erradicación del mercantilismo, culminando con la condena del Estado de bienestar. Al final de cuentas, la teoría económica pura validó su pureza cuando apartó de su seno a la política.

La teoría pura de la economía se debe acreditar al discípulo francés de Adam Smith, Jean-Baptiste Say (1841); para quien la política y la economía han estado indebidamente confundidas, siendo que la primera trata de la organización de las sociedades, en tanto que la economía versa del modo cómo se forman, distribuyen y consumen las riquezas. Say (1841:5), destaca que "las riquezas son esencialmente independientes de la 
organización política", porque el Estado puede ser próspero bajo cualquier forma de gobierno a condición de que esté bien administrado. Esto explica por qué hay monarquías boyantes, junto con repúblicas arruinadas. La libertad política puede ser favorable al desarrollo de la riqueza, pero sólo de manera indirecta. Hay que distinguir, por consiguiente, la importancia de los principios del buen gobierno y las bases del incremento de las riquezas.

La pureza de la política y la pureza de la economía implican su mutua exclusión, así como una actitud recíprocamente refractaria, que se plantea como una inevitable disyuntiva: ¿es posible hoy día un gobierno sin economía, del mismo modo que un gobierno sin política? La respuesta es no en ambos casos. Debe más bien buscarse un punto de conciliación en el cual converjan la política y la economía, como energías sustanciales del gobierno.

\section{Una imagen básica}

Sin embargo, la nueva gerencia pública representa la culminación glorificada del distanciamiento entre la economía y la política. Esto se puede percibir rítidamente, a través de sus conceptos fundacionales: orientación al cliente, privatización, mercado y competencia. Sucedáneamente es observable en el aparato de sistematización de la reforma neogerencial del sector público. Los conceptos son: enfoque empresarialgerencial, gerencia por objetivos y resultados, y agenciación. Finalmente, lo dicho también es visible en el móvil que anima a la nueva gerencia pública: reducir costos.

\subsection{Conceptos Fundacionales}

Hay que resaltar que la cuarteta conceptual alrededor de la cual se halla configurada la nueva gerencia pública, es la orientación al cliente, la privatización, el mercado y la competencia.

Orientación al cliente: Uno de los conceptos que mejor permiten identificar los fundamentos neoliberales de la nueva gerencia pública, es la soberanía del consumidor. La idea parte del hecho de que estando los ciudadanos influidos principalmente por el disfrute de bienes tutelares, como la educación, la salud y otros servicios brindados por el Estado benefactor, de allí emerge el problema de cómo financiar un enorme gasto con cargo a los ingresos del erario público (Organisation for Economic Cooperation and Development, 1987: 27-31). La solución se materializó en la orientación hacia el cliente, una versión actualizada de la idea de la soberanía del consumidor formulada originalmente por Ludwig von Mises. 
Uno de los propósitos esenciales de las reformas neogerenciales consiste en hacer que la administración pública esté en contacto con los clientes y así establecer en su seno un mercado competitivo. Como se supone que la definición de los objetivos de la administración pública suele ser opaca, su capacidad de respuesta (responsividad) requiere un estilo administrativo distinto. Es decir, una gerencia responsiva que capte la capacidad de cada cliente para acceder a las prestaciones que tienen derecho a esperar, pues se ha desarrollado una sutil división entre "usuarios de los servicios" y "consumidores de los servicios". Estos últimos, en contraste con aquellos otros, no son concebidos como recipientes pasivos de servicios, sino como clientes activos.

La idea de cliente sustituye a la noción de ciudadano, haciendo que como contribuyentes informados conozcan el nivel de eficiencia de los servicios públicos a través del pago de sus impuestos. Por tal motivo, los resultados electorales estarán determinados más por la satisfacción o insatisfacción con los servicios públicos, que por la politización, las campañas políticas y la opini ón pública.

Una de las nociones más ligadas a la soberanía del consumidor es el empoderamiento del cliente. El término tiene hondas raíces en la cultura política occidental, donde significa lo que un locutor o escritor desea transmitir cuando externa su opinión. Denota sencillamente la existencia de un gobierno democrático y con organizaciones abiertas a la participación de sus miembros. Sin embargo, en las reformas neogerenciales el empoderamiento ha tendido a referir meramente la condición de cliente y evocar la soberanía del consumidor, pues su despliegue obedece a las críticas hechas a un gobierno opaco, remoto e infranqueable. Siendo soberano, el consumidor asume el control de su vida y su destino, y de tal modo hace a su gobierno transparente y próximo (Peter, Guy and Pierre Jon, 2000: 9-11 y 24-25).

Como derivación de la orientación al cliente, que entraña el mejoramiento de la información de sus preferencias en el mercado, la administración pública sufre alteraciones significativas para tal efecto: las grandes organizaciones que suministran los servicios públicos se desagregan en pequeñas agencias operativas, toda vez que son extintos los monopolios gubernamentales. Siendo esas agencias las receptoras directas de las preferencias clientelares, junto con ellas se establecen pagos directos al usuario que tienden a sustituir a los impuestos (Hood, 1987: 145-170).

Privatización: El nuevo paradigma constituye un esfuerzo hacia la privatización de los estilos de la práctica gerencial, que demanda la adopción de las herramientas provenientes del sector privado por parte del sector público (Hood, 1991:3). La nueva 
gerencia pública se mueve hacia el aumento de la competencia en el sector público, porque la "rivalidad" es la clave de la disminución de costos y de mejores estándares. Por lo tanto, se esfuerza por disminuir o revertir el crecimiento del gobierno con base en un cambio hacia la privatización o cuasi-privatización (Hood, 1991:3).

La nueva gerencia pública se propone reemplazar al viejo paradigma vigente de la administración pública, idea emanada de la combinación de la perspectiva gerencial y una nueva apreciación del sector público, que descansa en el propósito de establecer un mercado interior y privatizar la provisión de bienes y servicios públicos. Este propósito tiene su raíz en la clausura de la fase de la exoprivatización y la inauguración de la etapa de la endoprivatización, tal como se puede visualizar en el siguiente pasaje: “dado que todas las actividades del gobierno difícilmente pueden ser transferidas al sector privado, la próxima mejor solución es transferir la orcaneta de los negocios a las operaciones gubernamentales. Sin embargo, el manejo privado es diferente de la administración pública: el primero deriva de las operaciones comerciales y significa traer un nuevo espíritu y un nuevo vocabulario, así como la proliferación de las técnicas de su manejo. Esto también significa "desburocratizar" las operaciones del gobierno y reducirlas substancialmente" (Savoie, 1995: 113).

En efecto, la nueva gerencia pública es el resultado de un proceso constituido por dos etapas de privatización de los espacios públicos. La primera entraña la exoprivatización del Estado y consiste en el procedimiento por el cual la administración pública transfiere la producción de bienes y servicios a la administración privada, moviendo al Estado hacia fuera del mercado. La segunda etapa consiste en la endoprivatización del Estado, es decir, la sustitución de la administración pública de los asuntos nacionales, por la idea, la metodología y la técnica de la gerencia privada, moviendo al mercado hacia dentro del Estado.

En la exoprivatización la gerencia pública fungió como el sujeto de la transacción de cosas hacia el mercado; en la endoprivatización esa gerencia se convierte en el objeto de la transacción mercantil. En la primera etapa la gerencia pública es el mercader, en la segunda es la mercancía. En tanto la exoprivatización afecta al qué de la administración pública, la endoprivatización lo hace con el cómo.

Mercado: La nueva gerencia pública establece mercados interiores en el seno de la administración pública, y utiliza la contratación para fomentar la competencia. Esta fórmula se extiende a la administración de personal donde se ha impuesto el sistema de contratos (Boyle, 1992-1993: 333-336), y así allana el paso al servicio civil para 
incorporar candidatos del sector privado (Gray y Bill, 1995:87).

La visión neogerencial refleja el crecimiento sobresaliente de los valores del mercado en el sector público. Este enfoque tiene su base en el modelo de conducción del mercado dentro del sector público, y aunque la provisión de bienes y servicios no es nueva en dicho sector, la forma en que se hace lo es, porque hay un estilo diferente de organización y liderazgo que está fundado en el desarrollo mercantil interior. El cambio consiste en mudar algunas funciones tradicionales en el sector público y establecer en su interior los elementos del mercado. Esa mutación está representada por la gerencia, en lugar de la asignación pública de recursos; por la privatización, en lugar de las empresas públicas; por esquemas de incentivos de competitividad, en lugar de la distribución de impuestos; por la desregulación, en lugar de la regulación; y por la economía neoclásica, en lugar de la hechura de política pública (Lane, 1994:140).

La neogerencia pública representa un cambio de foco de la privatización, la cual, de actuar originalmente hacia fuera, retorna y se introduce en los procesos de gestión pública para establecer un mercado interior, pues su objeto es explotar a los sectores públicos de los países que tienen una economía avanzada, donde el tamaño de la asignación de recursos públicos es substancial y cuentan aún con empresas públicas. En efecto, el manejo público es un intento de reforma del sector público desde dentro, en tanto que la privatización implica que las funciones son segregadas del sector público (Lane, 1994:142). La privatización favorece el mercado externo, en tanto que el modelo neogerencial auspicia el mercado interno. Sencillamente la privatización ha cambiado de lugar, pues ha pasado de fuera, hacia dentro. De aquí nuestra idea de diferenciar, como lo hicimos saber, entre exoprivatización y endoprivatización.

Por lo tanto, uno de los efectos preponderantes del imperio del mercado consiste en el establecimiento de sus mecanismos dentro de la administración pública, entre los que destacan la contratación por fuera (contracting out) y los cargos al usuario 1 . Este último constituye una de las manifestaciones más nítidas de la orientación al cliente, toda vez que entraña mecanismos típicos de mercado y competencia. Hay que agregar los vales (vouchers), que constituyen un régimen a través del cual el cliente adquiere el derecho a un bien o servicio que él puede cubrir a los proveedores, y que reembolsan en moneda o en su equivalente desde un fondo destinado al efecto (Ormon, 1998:7-9).

\subsection{Competencia}

La competencia cierra el cuadrángulo básico del esquema conceptual de la nueva gerencia pública, que integra con la orientación al cliente, la privatización y el mercado, 
Bajo los lineamientos de la nueva gerencia pública, las organizaciones de la administración pública son rediseñadas dentro de los modelos económicos del sistema de contrato, como en las empresas privadas. Es decir, se crean corporaciones competitivas que buscan buenos precios y costos bajos, de manera que estas corporaciones públicas tienen más una configuración lucrativa, que una orientación de interés público. Por consiguiente, la competencia es crucial porque se discierne que provee la insistencia necesaria para dar eficiencia a los servicios públicos, e incentivar a las organizaciones estatales para que sean competitivas como proveedoras del gobierno y con los proveedores del sector privado. Por tal motivo se elimina la protección monopólica que los gobiernos brindaban a sus proveedores y se establecen servicios con base en el sistema de precios (Kaul, 1997:18).

Debido a que la neogerencia pública es categorizada como una reconceptuación normativa de la administración pública, se presume capaz de proveer servicios de alta calidad para los valores ciudadanos e incrementar la autonomía de los manejadores públicos, pues esos servicios son tan competitivos como los propios de la empresa privada (Borins, 1995: 131-132). Por lo tanto, ella se propone mejorar la visión de los problemas públicos del gobierno a través de fuerzas poderosas, entre las que destacan la privatización y la competitividad (Boyne, 1996:686).

La nueva gerencia pública tiene en la orientación al cliente el espacio de proximidad que requiere para poner vis a vis al proveedor y al consumidor. La privatización refrenda el papel eminente de la propiedad y la lucratividad que emanan del capitalismo, en tanto que el mercado se ofrece como el ámbito de intercambio y de transacción para los actores del drama económico que bulle en la administración pública cataláctica, cuya garantía es una competencia proverbial.

\subsection{Aparato de Sistematización de la Reforma Neogerencial del Estado}

El enfoque empresarial-gerencial, la gerencia por objetivos y resultados y la agenciación, configuran la base organizativa y operacional del nuevo manejo público.

Enfoque empresarial-gerencial: La nueva gerencia pública constituye un paradigma de gestión que combina los papeles de empresario y gerente. Entraña un modelo empresarial de manejo del sector público, pues la expresión inglesa public management es el reflejo de la inserción de la perspectiva gerencial dentro del sector público (Savoie, 1995:112). Esto significa la implantación de la imagen empresarial de los negocios privados dentro del gobierno, cuya idea es que el sector público esté en manos de gerentes profesionales dotados con un control activo, visible y discrecional sobre las 
organizaciones (Lane, 1994:139). Es un modelo que invoca la libertad de manejo como paráfrasis de la idea de la libertad de elegir, formulada por Milton Friedman (1979), de lo cual deriva su propuesta sobre la responsabilidad que requiere una asignación clara de deberes, no la dispersión del poder.

Gerencia por objetivos y resultados: El modelo neogerencial desarrolla un diseño de objetivos por resultados, donde se formulan estándares explícitos y medidas de rendimiento, así como la definición de metas e indicadores de éxito, preferentemente expresados en términos cuantitativos. La noción de responsabilidad es configurada con base en una declaración nítida de metas, de modo que se pone énfasis en los controles de resultados, en tanto que la asignación de recursos se asocia a medidas de rendimiento. Asimismo se anteponen los resultados a los procedimientos, y se enfatiza la importancia de la evaluación y la eficiencia.

Agenciación: La estrategia organizativa del neogerencialismo para establecer los lineamientos catalácticos en la administración pública, consiste en desagregarla en una diversidad de agencias que operan con base en el pago por servicio. Esa administración, de suyo centralizada, es desarticulada en unidades menores para operar con libertad y flexibilidad. Se impone un cambio hacia la desagregación de la organización del sector público y el desgajamiento de unidades monolíticas, para establecer un sistema gerencial uniforme dentro de unidades corpóreas integradas alrededor de productos. Las nuevas entidades operan con base en presupuestos descentralizados sobre una sola línea, de aquí que se establezcan unidades manejables merced a la separación de los intereses propios de la provisión y de la producción. A través de estos mecanismos se esperan ventajas derivadas del uso de contratos y franquicias, tanto dentro como fuera del sector público (Hood, 1991:5-6).

La importante noción de consumidor s del sector público para "hacer más conoberano determina directa y decisivamente las reformas de la administración pública bajo la égida neoliberal. La agenciación es uno de sus frutos más representativos, pues mediante esta organización en pequeña escala es como se pueden captar con mayor nitidez las preferencias del consumidor (Hood, 1987: 148).

Reducción de Costos: Como corolario de todo lo anterior, el fin supremo que se persigue consiste en disminuir los gastos del gobierno. Con miras en este objeto se acrecienta la presión hacia un gran rigor en el manejo de los recursos, la reducción de costos, el reforzamiento de la disciplina laboral y la resistencia a las demandas sindicales. De aquí emana el control de las demandas de recursos menos". En suma: el propósito 
básico del gobierno neogerencial consiste en ensanchar la eficiencia en la asignación de los recursos públicos (Hood, 1987: 146).

Con base en este ideario así reseñado, la hermandad académica neogerencial concluye lo siguiente: todo lo anterior demanda que el gobierno sea removido del nicho de la administración pública, donde opera con reglas y jerarquía, limita la libertad de acción, coarta la capacidad de respuesta y restringe la iniciativa. Su nuevo sitial debe ser la nueva gerencia pública, la cual brinda al gobierno un sentido de adaptación e innovación institucionales, y lo transforma en más flexible y más responsivo en el despacho de sus labores.

En suma: la nueva gerencia pública consiste en un ente que está constituido de manera polarmente opuesta a la administración pública como se observa en el cuadro siguiente:

En efecto, la nueva gerencia pública consiste en un modelo constituido de manera polarmente opuesta a la administración pública, pues ésta tiene como principio causal la política, su foco organizativo es el Estado, con sus relaciones de dominación; y su núcleo procesal es la jerarquía, es decir, una cadena de delegación. En tanto que en la nueva gerencia pública, la economía es la unidad de objeto, el mercado con sus relaciones de intercambio es el foco organizativo, y la catalaxia es el núcleo procesal con sus relaciones contractuales. El corazón activo de la administración pública es el servicio público, para la gerencia lo es el mercado; la primera tiene una vocación regulatoria y está normada por el derecho administrativo, la segunda está inspirada en la desregulación y su escenario formal es el derecho mercantil. La administración pública detenta sus valores en la ética y produce un efecto social de bienestar colectivo, en tanto que la gerencia exalta la eficacia y su efecto económico se orienta al elogio del individualismo. La primera es pública y colectiva, la segunda privada y egoísta. La una está basada en una disciplina dentro de las ciencias sociales, la otra es una transdisciplina económica que ha colonizado a la administración pública.

\section{Catalaxia}

La naturaleza cataláctica de la nueva gerencia pública obedece a su índole mercantil, pues ella es la emanación de una economía que la sitúa en el mercado como su mundo existencial. Esto es lo que le brinda su carácter de nexo y de exterioridad, pues ella se explica fuera de la organización, no dentro. Es decir: el mercado es su condicionante esencial, porque es el intercambio el que nutre su vida. Sin embargo, aunque la neogerencia pública está determinada por su carácter mercantil, desde el momento en que se adentra en el cosmos organizativo de la administración pública es vigente en ella el 
mismo efecto que sufre la gerencia privada en el seno de la empresa. A saber: el proceso cataláctico se desvanece y es sustituido por el proceso jerárquico, de manera que los precios dejan de operar como homeóstato del intercambio mercantil, para ser reemplazada por el papel del empresario como gerente. Es de tal modo que la coordinación brindada por el sistema de precios, que mueve a la empresa desde fuera, es suplida por la gerencia que es activada desde dentro.

\begin{tabular}{|c|c|c|}
\hline \multicolumn{3}{|c|}{ Diversidades entre la administración pública y la nueva gerencia publica } \\
\hline Cáracter Distintivo & Administración Pública & Nueva Gerencia Pública \\
\hline Principio Causal & La Politica & La economía \\
\hline Foco Organizativo & $\begin{array}{l}\text { El Estado: } \\
\text { Relaciones de dominación }\end{array}$ & $\begin{array}{l}\text { El mercado: } \\
\text { Relaciones de intercambio }\end{array}$ \\
\hline Núcleo Procesal & $\begin{array}{l}\text { La jerarquia: } \\
\text { Cadena de delegación }\end{array}$ & $\begin{array}{l}\text { La catalaxia: } \\
\text { Contrato }\end{array}$ \\
\hline Corazón Activo & Servicio público & Competencia \\
\hline Fundamento Jurídico & Derecho administrativo & Derecho mercantil \\
\hline $\begin{array}{l}\text { Orientación hacía } \\
\text { el ser humano }\end{array}$ & Lo público & Lo privado \\
\hline Fundamento axiológico & $\begin{array}{l}\text { La ética: } \\
\text { Bienestar público }\end{array}$ & $\begin{array}{l}\text { La eficiencia: } \\
\text { Individualismo }\end{array}$ \\
\hline Naturaleza cientifica & Ciencia social & Transdisciplina económica \\
\hline
\end{tabular}

Existe pues una paradoja existencial en la nueva gerencia pública: siendo cataláctica su índole, es decir, un intercambio libre, horizontal, espontáneo y automático, su paso hacia dentro de una organización la somete a reglas coercitivas, verticales, deliberadas y planeadas. Esta paradoja, que es explicada por R.H Coase (1963), es resuelta en principio por Ludwig von Mises.

\subsection{La Coordinación Gerencial del Empresario}

Como todo economista, Coase (1963:304), partió de la descripción del sistema económico como algo que normalmente funciona por sí mismo, es decir, que su operación ordinaria no está sujeta a ningún control central, ni necesita de supervisión céntrica, pues a través de un proceso automático la oferta se adapta a la demanda, y la producción al consumo. Por consiguiente, él observa al sistema económico como un ente coordinado por el mecanismo de precios. Pero, aunque dicho sistema funciona por sí mismo, esto no significa que no exista en su interior alguna planeación debida a personas que prevén y 
optan entre alternativas a seguir, pues tal es la condición necesaria del orden imperante en el sistema.

Hasta allí no existe ningún problema. Las dificultades comienzan cuando se trata de explicar la coordinación en el seno de la empresa, donde el mecanismo coordinador no son los precios. Este punto es el aspecto más complicado cuando se parte desde el ángulo del mercado, y se penetra dentro de la empresa donde el mercado se desvanece junto con su sistema de precios. Esta compleja situación no ha sido desatendida por economistas de la talla de Alfred Marshall (1931: Caps. XVIII-XII), quien propuso a la organización como el cuarto factor de la producción $\underline{2}$.

Debido a que en el seno de la empresa las transacciones de intercambio son inexistentes, la estructura del mercado es reemplazada por el empresario coordinador que maneja la producción. Esto hace evidente que hay dos formas de coordinación diversas, ya se trate de fuera o de dentro de la empresa. Existe una coordinación propia del mecanismo de los precios y una más por obra del empresario (Coase, 1963:305-306). Estando fuera de la empresa, la coordinación es un campo del saber de economistas neoclásicos del prestigio de Friedrich Hayek. Estando dentro, la coordinación es una materia de administradores privados de crédito elevado como el de Lyndall Urwick.

Por consiguiente, hay que resaltar que el rasgo característico, distintivo y preponderante de la empresa radica en la función de reemplazo del mecanismo de precios (Coase, 1963:306). Con base en esta función, el empresario es definido como la persona que en un régimen mercantil de competencia sustituye al mecanismo de precios en el manejo de los recursos (Coase, 1963:307-309), en calidad de gerente.

Esta función coordinadora del empresario, formulada por Coase en 1937, había sido desarrollada desde 1916 por Henri Fayol a través de su concepto de administración como prever, organizar, mandar, coordinar y controlar (Fayol, 1931). Pero que fue desenvuelta de un modo más sintético a través del teorema de Urwick, por el cual se declara que el fin de la organización es la coordinación, pues sin ella la división del trabajo se convierte en un fenómeno caótico, errático y azaroso (Urwick, 1942).

En suma: el régimen de mercado competitivo sólo existe fuera de la organización, y cuando más se extiende como un nexo coordinador entre organizaciones, pues cuando se trata del interior de la empresa, el mercado y el mecanismo de precios cesan de existir, siendo este el locus de un empresario que ejercita la coordinación como gerente en el sentido de Urwick. 
De acuerdo con todo lo anterior, resulta claro que la propuesta de la nueva gerencia pública por cuanto que es posible introducir el mercado y la competencia en el seno de la administración pública debe examinarse atentamente, pues esa posibilidad es de suyo irrealizable incluso en la empresa privada.

\subsection{La Gerencia}

Debido a la paradoja de la imposibilidad de que el mercado coordine internamente a la empresa a través del mecanismo de precios, requiriendo de empresarios-gerentes que coordinen, la nueva gerencia pública por cuanto cataláctica no siguió el camino de Urwick, es decir, la interioridad de la esfera de la producción, sino el ámbito del intercambio. Esto ha derivado en una estrategia de reforma de la administración pública acomodada al mercado que no ha desarrollado una teoría gerencial clásica, sino una visión alterna que optó por simplificar su estructura a través de un proceso quirúrgico, por el cual son desagregadas las grandes organizaciones burocráticas en unidades operativas.

Este diseño obedece a los cánones sacrosantos de la economía neoclásica que proclama, como ocurre en la empresa privada, que las agencias públicas estén relacionas directamente con los clientes. Previamente los ciudadanos son concebidos como consumidores situados en el mercado, los cuales pagarán directamente los servicios así brindados, toda vez que el sistema de precios produce la información necesaria para que los proveedores capten sus preferencias. Sin embargo, esas grandes organizaciones administrativas no desaparecen, se reforman, de manera que la coordinación interna se confía en gerentes públicos preparados de manera similar a los manejadores privados.

Es a través de tal estrategia, que la gerencia pública cataláctica es introducida en el Estado.

\subsection{Catalaxia: el Cálculo Monetario}

La catalaxia es el factor de definición esencial de la gerencia privada, pues ella se ocupa de las acciones económicas realizadas sobre la base del cálculo monetario. Pero el intercambio mercantil y el cálculo monetario se hallan mutua e inseparablemente ligados, porque la presencia del dinero y del cálculo monetario está condicionada por la preexistencia del mercado. Catalaxia es la teoría de los tipos de intercambio y de los precios (Mises, 1996: Cap XIV parte 1 y Cap XVI parte 1).

Gerencia cataláctica es, por consiguiente, el manejo cuya operación se realiza con base en un cálculo monetario que tiene su sede causal en las relaciones mercantiles. Es aquella 
gerencia donde cada persona cooperante es evaluada en función del valor de su contribución en el proceso de producción de bienes y servicios. Salarios y sueldos no dependen de decisiones arbitrarias, sino de los mandatos de los consumidores dictados desde el mercado, lo mismo que las mercancías que brotan de los procesos productivos de la empresa. Es el consumidor soberano quien manda sobre los empresarios, los agricultores y los trabajadores, cuyas ganancias, pérdidas y salarios, están determinados por los procesos mercantiles. La fuerza de su mandato no deriva de que involucre a personas relacionadas en el proceso de producción, sino a las cosas que ese proceso implica. La gerencia cataláctica “concierne a las cosas, no a los hombres" (Mises, 1996: 38).

Se trata de la gerencia de las cosas anunciada muchos años antes por Henri de SaintSimon (1975), donde se gestiona sin prejuicio ni pasión, y con la pura objetividad de tratar con materiales inanimados.

\section{Conclusión}

La nueva gerencia pública culminaría ese ancestral anuncio hecho por Saint-Simon, en el sentido de que la administración de las cosas finalmente reemplazaría al gobierno de los hombres. ¿Habrá ocurrido tal cosa? Creo que no, porque una administración tal, significa la visión romántica de un gobierno sin política.

1. La contratación por fuera es el traspaso de la provisión de servicios al sector privado, en tanto que el cargo a los usuarios es el pago directo de los servicios públicos que realizan para hacerles conocer inmediatamente sus costos y beneficios (Ormon and Elke, 1998).

2. Marshall (1928) también destinó un capítulo al estudio del manejo en los negocios. El capítulo referido es el XII, cuyo contenido trata de la organización industrial y el manejo de negocios (business management).

\section{Referencias Bibliográficas}

1. Barnard, Chester (1975), The Functions of Executive. Harvard University Press. (1938).

2. Borins, Sanford (1995), "The New Public Management is Here to Stay". Ottawa, Canadian Public Administration Review. Vol. 38, num. 1. pp. $121-132$.

3. Boyle, Richard (1992-1993), "Managing by Contract in the Public Sector". Dublin, 
Administration. Vol 40, num. 4. pp. 333-346.

4. Boyne, George (1996), "The Intellectual Crisis in British Public Administration: is Public Management the Problem or the Solution?". United Kingdom, Public Administration. Vol. 74, Winter. pp. 679-694.

5. Buchanan, James (1991), “Politics without Romance: A Sketch of Positive Public Choice Theory and Normative Implications". Petit, Philip [Edit.]. Contemporany of Political Theory. New York, Macmillan Publishing Company.

6. Cantillon, Richard (1950), Ensayo sobre la Naturaleza del Comercio en General. México, Fondo de Cultura Económica. (1755).

7. Coase, R.H. (1963), “La Naturaleza de la Empresa”. Stigler, G.J. y K.E. Boulding. Ensayos sobre la Teoría de los Precios. Madrid, Edit. Aguilar. pp. 303-321.

8. Drucker, Peter (1986), Managing for Results. New York, Harper and Row Publishers. (1964).

9. - - - - (1969), The Age of Discontinuty: Guidelines to Our Changing Society). New York, Harper and Row, Publishers.

10. Fayol, Henri (1931), Administration Industrialle et Générale. Paris, Dunod. (1916).

11. Friedman, Milton and Friedman, Rose (1979), Free to Choose. New York, Harcourt Brace Jovanovich.

12. Frye, Charles (1966), "Carl Schmitt's Concept of the Political". United States, The J ournal of Politics. Vol. 28, num. 4. pp. 818-830.

13. Gelinier, Octave (1967), El Secreto de las Estructuras Competitivas. Madrid, Ediciones Tea. (1965).

14. Gray, Andrew and Bill Jenkins (1995), "From Public Administration to Public Management: Reassesing a Revolution". United Kingdom, Public Administration. Vol. 73, Spring. 1 pp. 75-99.

15. Hayek, Friedrich (1944), The Road to Serfdom. Chicago, University of Chicago Press. 
16. Hood, Christopher (1987), “British Administrative Trends and the Public Choice Revolution". Lane, Jan-Erik (Ed.). Bureaucracy and Public Choice. London, Sage Publications. pp. 145-170.

17. Hood, Christopher (1991), "A Public Management for all Seasons?". United Kingdom, Public Administration. Vol 69, num. 1. pp. 3-19.

18. Kaul, Mohan (1997), “The New Public Administration: Management Innovations in Government". London, Public Administration and Development. Vol. 17, num. 1. pp. 13-26.

19. Kelsen, Hans (1933), La Teoría Pura del Derecho. México, Edit. Colofón.

20. Kotter, John (1982), The General Managers. New York, The Free Press.

21. Lane, Jan-Erik (1994), "Will Public Management Drive Out Public Administration". Japan, The Asian Journal of Public Administration. Vol. 16, num. 2. pp. 139151.

22. Laufer, Romain et Alain Burlaud (1980), Management Public: Gestion et Legitimité. Paris, Delloz.

23. Marshall, Alfred (1931). Principios de Economía. Barcelona. El Consultor Gráfico (1920, $8^{\circ}$ edición). Dos tomos. Libro IV.

24. Marshall, Alfred (1928), Elements of Industry. London, MacMillan and Co. Limited. Dos volúmenes en un tomo.

25. Messenet, Michel (1975), La Nouvelle Gestion Publique: Pour un Etat sans Burocratie. Paris, Editions Hommes et Tecniques.

26. Mintzberg, Henry (1983), La Naturaleza del Trabajo Directivo. Madrid, Edit. Ariel.

27. Mises, Ludwig von (1994), Liberalismo. Madrid, Planeta Agostini. (1927).

28. Mises, Ludwig von (1988), Intervencionism. New York, The Foundation for Economic Education (1940).

29. Mises, Ludwig von (1996), The Human Action. Foundation for Economic 
Education. (1949). Htt:/www. mises.org/ humanaction.asp.

30. Niskanen, William (1971), Bureaucracy and Representative Goverment. Chicago. Aldine Atherton.

31. Organisation for Economic Cooperation and Development (1987). The Administration as Service the Public as Client. Paris.

32. Ormon, Derry and Löffler, Elke (1998), “New Public Management: what to take and what to leave". Madrid, Spain. III International Conference of CLAD on State and Public Administration Reform. October 14-17.

33. Ostrom, Vicent (1974), The Intelectual Crisis in American Public Administration. The University Alabama Press.

34. Peters, Guy and Pierre, Jon (2000), "Citizens versus The New Public Managers: The Problem of Mutual Empowerment". United States, Administration \& Society. Vol. 32, num. 1. pp. 9-28.

35. Saint-Simon, Henri (1975), El Sistema Industrial. Madrid, Ediciones de la Revista del Trabajo (1821).

36. Savoie, Donald (1995), “What is Wrong with the New Public Management"'. Canada, Canadian Public Administration Review. Vol. 38, num. 1. pp. 112-121.

37. Say, Jean-Baptista (1841), Traité d’Economie Politique. Paris, Guillaumin, Libraire. Sixième edition.

38. Sayles, Leonard (1964), Managerial Behavior. New York, McGraw-Hill.

39. Schmitt, Karl (1985), El Concepto de lo Político. México, Folios Ediciones. (1932).

40. Smith, Adam (1952), An I nquiry into the Nature and Causes of the Wealth of the Nations. Chicago, Encyclopaedia Britannica, Inc. (1776).

41. Sheldon, Oliver (1986), La Filosofía del Management. Barcelona, Ediciones Orbis. (1923).

42. Taylor, Frederick (1911), The Principles of Scientific Management. New York, 
Harper and Brothers Publishers.

43. Tullock, Gordon (1965), The Politics of Bureaucracy. Washington. Public Affairs Press.

44. Urwick, Lyndall (1942), The Elements of Administration. New York, Harper and Brothers Publishers. 